\title{
Working from the Inside Out: Fostering Intrinsic Motivation and Expanding Our Criteria for Conservation Success
}

\author{
Claire Cardinal $^{1}$ (D) Miranda A. Strubel ${ }^{1} \cdot$ Aimee S. Oxley $^{2}$
}

Received: 5 April 2021 / Accepted: 20 January 2022 / Published online: 8 February 2022

(C) The Author(s), under exclusive licence to Springer Science+Business Media, LLC, part of Springer Nature 2022

\begin{abstract}
Primatological research is often associated with understanding animals and their habitats, yet practical conservation depends entirely on human actions. This encompasses the activities of Indigenous and local people, conservationists, and NGOs working on the ground, as well as more remote funders and policymakers. In this paper we explore what it means to be a conservationist in the 2020s. While many primatologists accept the benefits of more socially inclusive dimensions of research and conservation practice, in reality there remain many challenges. We discuss the role primatologists can play to enhance interdisciplinary working and their relationships with communities living in and around their study sites, and examine how increased reflexivity and consideration of one's positionality can improve primatological practice. Emphasis on education and stakeholder consultation may still echo colonial, top-down dialogues, and the need for greater emphasis on genuine knowledge-sharing among all stakeholders should be recognised. If we are sincere about this approach, we might need to redefine how we see, consider, and define conservation success. We may also have to embrace more compromises. By evaluating success in conservation we explore how reflexive engagements with our positionality and equitable knowledge-sharing contribute to fostering intrinsic motivation and building resilience.
\end{abstract}

Keywords Human-primate interactions · Knowledge sharing · Positionality · Ethnoprimatology $\cdot$ Reflexivity $\cdot$ Resilience

Claire Cardinal and Miranda A. Strubel joint first author

Handling Editor: Joanna Setchell

Claire Cardinal

claire.cardinal-2017@brookes.ac.uk

1 Faculty of Humanities and Social Sciences, Oxford Brookes University, Headington Campus, Oxford OX3 0BP, UK

2 Department of Field Conservation and Science, Bristol Zoological Society, Bristol Zoo Gardens, Clifton, Bristol BS8 3HA, UK 


\section{Introduction}

The purpose of this Special Issue is to highlight some of the challenges that primatologists face while conducting conservation-centred research, and to provide insights from current practice that develop awareness and offer guidance to help our work become more applicable in practical primate conservation. We all may feel frustrated and powerless at times, but how can we increase the effectiveness of our work so that it leads to conservation outcomes that are beneficial for both the nonhuman primates and people inhabiting our diverse biocultural landscapes? Here, we consider this question from the perspective of those carrying out research aimed towards primate conservation, particularly fieldworkers whose work involves local communities. This paper brings together a range of perspectives and approaches from fields and disciplines beyond primatology. By connecting important concepts, such as reflexivity, positionality, knowledge-sharing and resilience, we identify factors that can assist us in achieving greater impact as natural and social science researchers/practitioners engaging in human-nonhuman primate work.

We recognise that many readers will come from a natural sciences background, while others will be trained social scientists. However, many researchers and practitioners, particularly in biosocial subfields, identify with/as both and draw from different disciplines using a combined approach and a variety of methods. Montana et al. (2019) identified pronounced within-group variability when investigating research preferences among conservationists, and suggested that the binary distinctions drawn between natural and social science categories were inadequate to describe the diversity of their disciplinary backgrounds. In recognition of the increasing heterogeneity of primatologists and the diverse knowledge systems they reflect, this article is directed towards a broad readership, and aims to include all those with interests in primate conservation (e.g. primatologists, ethnoprimatologists, biologists, ecologists, conservationists, social scientists, biosocial researchers - researchers and practitioners alike).

As early-career researchers ourselves, the question of how to generate more effective solutions that benefit both humans and nonhuman primates is something we actively ponder and discuss, reflecting on the decades of research we are building on, while witnessing the generally declining state of species and forests. In an effort to actively address this question, we delve deeper into what constitutes "success" in conservation, the factors that are important for success, and how we can develop a vision of success that incorporates the viewpoints of various different stakeholders.

Crucial to this inquiry is the acceptance that our pre-existing constructions of success are shaped by our positionality, as well as the larger system of which we are part. In this context, Klages (2010) considers the dilemma presented by nonhuman primate conservation and human poverty alleviation, questioning what the right choice is and for whom? As he reminds us, the answer depends on who the question is being directed towards. What success is and looks like is often unclear, and is deeply determined by the positionality of the person asking the question.

Increasingly funders and conservation agencies emphasise the need to demonstrate and evaluate the impact and sustainability of conservation projects (Howe \& 
Milner-Gulland, 2012; IUCN, 2016b). Not only does this necessitate projecting and anticipating success criteria at the beginning of a project, but it necessarily relies upon us defining success within our own frames of reference before we have fully understood the various perspectives of local stakeholders. As a result, this can lead scholars to be overly ambitious when stating their conservation objectives and outcomes, especially for short-term research, as they endeavour to demonstrate the importance of their research and its ability to meet academic or funding priorities.

Success has been measured in a variety of ways by different actors engaged in wildlife conservation. For example, the progress of species recovery programmes can be assessed against the legacy of past conservation activities and on-going dependency on conservation, anticipated medium term population gains, and longterm recovery potential (Akçakaya et al., 2018). The IUCN requires initiatives that it supports to be evaluated in terms of their relevance, effectiveness, efficiency, sustainability, and impact (IUCN, 2016a, 2016b). This reflects the "triple bottom line" approach, which represents a trade-off between environment, equity, and economy, translated in the conservation context as achieving conservation benefits, social equity, and value for money (Halpern et al., 2013; Klein et al., 2015). Brooks et al. (2006) identify four measures of conservation success - ecological, economic, behavioural, and attitudinal. We suggest that there is also a temporal aspect to success that affects the sustainability of primate conservation programmes. It often takes time for the impacts of conservation activities to manifest, and their effects on human and nonhuman communities are dynamic. Programmes therefore need to build in the capacity to assess and monitor patterns that emerge gradually over time.

For researchers involved in primate conservation, fieldwork frequently involves collaboration with local communities. Building trust and effective relationships necessitates a commitment to long-term engagement that is responsive to change and receptive to genuine partnership, and this is a crucial element of successful conservation outcomes. In recognition of the longstanding sympatry between humans and other primates (Fuentes, 2007; Loudon \& Sponheimer, 2016) and the complex nature of the human-nonhuman primate interface (Hardin \& Remis, 2006; Hill, 2002), the field of ethnoprimatology has focussed on these environments in order to understand what human-nonhuman primate interactions mean for all involved. Whilst this has greatly enhanced our understanding of multispecies interactions in shared habitats, there remains a gap in demonstrating to funders and other decisionmakers how this research aligns with conservation solutions. With this in mind, how might our role be more empowering - both to us and the local people we work with? How can we ensure that conservation solutions reflect the goals and needs of people living in proximity to the primates we seek to conserve?

In the following two sections of this article we discuss how we can enhance interdisciplinary working and how reflexivity can support primate conservation research and practice. We then consider the limitations of traditional conservation education approaches, and explore how knowledge-sharing with local and indigenous communities can support traditional lifeways and enhance conservation outcomes. Lastly, we propose the concept of resilience in measuring the success of conservation programmes. 


\section{Some Challenges of Working Within Interdisciplinary Frameworks}

The complexity of contemporary conservation issues demands more than any one discipline can offer and the social sciences can complement natural science approaches (Dore et al., 2018; Mascia et al., 2003). However, multiple obstacles have been identified and experienced when trying to cross disciplinary boundary lines, and the conservation social sciences are still misunderstood and underutilized, which dilutes their potential contributions to conservation projects and the achievement of more holistic solutions (Bennett et al., 2016). Perceived hierarchies of knowledge and dominance of the natural sciences mean that the social sciences are often under-valued in conservation (Adams, 2007; Setchell et al., 2017).

It has been argued that ideological, institutional, knowledge and capacity barriers prevent social sciences being mainstreamed across the conservation community, conservation organisations and global policy-making bodies, and that it is imperative that concerted action is taken to actualise integration (Bennett et al., 2016; Bennett et al., 2017; Fox et al., 2006). Many of the inhibitors to interdisciplinary research and conservation practices reflect a lack of understanding among prominent scholars from different fields, including differences between research cultures which lead to incompatible assumptions and approaches to a particular question or problem, uncertainty about the types of questions and methods each other use, and the use of unfamiliar language, terminology, or jargon which hinder communication (Fox et al., 2006; Parathian et al., 2018). A lack of funding for interdisciplinary approaches adds a practical disincentive (Fox et al., 2006).

Another stumbling block in conservation practice involves the stage of a project at which social scientists are invited to participate, with social scientists often only invited to collaborate towards the end of a project, as a form of tokenism or to meet a specific mandate (Campbell, 2005; Fox et al., 2006). Hackett and Rhoten (2009, p. 411) contend that interdisciplinarity can "stimulate fresh vision ... [and] provide the opportunity for unique and inventive knowledge to emerge at the interstices between the disciplines", something that is surely needed if primate conservationists are to address the dire situation of the world's primates. If we accept that conservation solutions depend on human actions, then it follows intuitively that interdisciplinary collaborations that incorporate both the natural and social sciences are essential to achieving success (Adams, 2007).

Ethnoprimatology has largely responded to the need for a more holistic approach to studies of human-primate relations, and its toolkit has expanded to incorporate a diverse array of methodologies and theoretical perspectives from ecological and anthropological disciplines (Fuentes, 2012; Riley, 2006, 2018). Progress has been made towards bringing about disciplinary inclusivity through, for example, the establishment of the IUCN-SSC Primate Specialist Group Section for Human Primate Interactions and the Social Sciences Working Group by the Society for Conservation Biology (Dore et al., 2018; Fox et al., 2006) and many of the articles cited in this paper provide excellent examples of the growing body of interdisciplinary research in conservation. However, the 
rapid growth and scale of anthropogenic drivers of habitat change (e.g. land-use change, habitat loss/fragmentation, human population increase, hunting, trafficking etc.) have led to calls for increased interdisciplinary collaboration and outside-the-box thinking (Dore et al., 2018; Parathian et al., 2018; Setchell et al., 2017). We advocate the use of theoretical and practical approaches from outside primatology and conservation, not only to expand the tools at our disposal when addressing these complex and diverse issues but also to broaden our perspectives in considering alternative viewpoints. Doing so will improve our research and enhance conservation success. Interdisciplinarity can be achieved either through collaborations of multiple people working across traditional disciplines or, less commonly, by individuals having expertise across different fields.

Broaching these disciplinary boundaries requires an understanding and appreciation that extends through primatology research, training, and conservation practice. Three elements are needed to facilitate interdisciplinarity: 1) better understanding of each other's terminology and underlying assumptions, 2) appreciating the skill sets each other can bring to the party, and 3) genuine collaborations in conservation research and practice. In pursuit of these goals, several useful articles have sought to demystify social sciences approaches for natural scientists, and we draw particular attention to three recent publications: Moon and Blackman (2014) provide a straightforward guide to the philosophical approaches used in anthropology; Parathian et al. (2018) discuss complementary approaches used in the natural and social sciences to investigate the human-nonhuman primate interface and include a useful glossary of their respective terminologies; and Setchell et al. (2017) review three conservation projects that integrate biological and ethnographic methods to illustrate how an integrated approach can work successfully. In an earlier publication, Hardin and Remis (2006) elaborate the benefits and challenges of integrating biological and cultural anthropology research in their longitudinal study of the human-nonhuman primate interface in Central African Republic. Their paper demonstrates the linkages between animal declines and human livelihoods, and illustrates the value of taking a collaborative, cross-disciplinary approach in elucidating patterns and dynamics at a small scale over time.

To support a more interdisciplinary approach, Adams (2007) and WelchDevine et al. (2014) advocate for a pedagogical model for conservation education based on integrative training to equip individuals to understand and appreciate perspectives across different lenses, with a focus on problem-solving and the ability to move easily between different knowledge domains. Integrative training promotes more holistic approaches to research that aim to encourage deeper understanding of the systemic problems driving ecological and species decline. Cross-disciplinary conferences and problem-solving events may also provide useful fora to nurture collaborations. Better understandings among researchers and practitioners across disciplines will enable stronger mutual appreciation in the face of concerns about integrity, rigour, and robustness. In the following section, we discuss how the concepts of positionality and reflexivity, which are fundamental in anthropological approaches, can enhance primatological endeavours. 


\section{Positionality of the Primatology Profession and Ourselves As Individual Researchers}

Many people involved in wildlife conservation come from some form of natural science background (Bennett et al., 2017; Dore, 2018; Setchell et al., 2017). They are trained to take an objective, hypothetico-deductive approach, using large sample sizes and statistical methods to produce quantifiable results (Setchell et al., 2017). This approach adheres to the positivist/post-positivist philosophy that only factual knowledge gained through empirical observation which is measurable and replicable is authentic or true. By contrast, in anthropology, practitioners are trained to acknowledge that they can never be truly objective, although some form of critical distance is essential for analysis (Engelke, 2017; Lenkeit, 2004). While multiple different paradigms exist in social science research, many contemporary anthropologists align more closely with an interpretivist philosophy that our understanding(s) of the world is socially and culturally constructed, and that the same phenomenon may have multiple different meanings; therefore, multiple truths can exist, depending on one's worldview (Eriksen, 2004; LeCompte \& Schensul, 1999; Peacock, 2001). The ideas, experiences, and discourses of different individuals and groups are thus contextually interpreted to understand these underlying meanings (Moon \& Blackman, 2014). Reflecting on our positionality requires us to look critically at the circumstances that shape our knowledge (Haraway, 1988; Rose, 1997). We recognise that many primatologists conduct research that is not field-based and does not involve human participants. However, reflexive practice carries relevance to all primatologists, as it helps to inform and develop a deeper awareness of the decisions they make in planning and conducting research and the conclusions they reach.

The drive to promote culturally sensitive and desirable approaches in the primatology profession prompts us to consider our own reflexivity and its impact on our research practices. Reflexivity is an approach that has long been considered in anthropology. Although earlier examples exist, the reflexive turn in the discipline started gaining momentum during the 1970s and reached prominence in the 1980s and 1990s (Collins \& Gallinat, 2010; Salzman, 2002). This was due to a complex confluence of influences, including concerns within the discipline surrounding ethnographic representation (Dominy, 2018), postmodernist critiques (Lavenda \& Schultz, 2000), and the 'treatment of ethnographic texts as texts' (Collins \& Gallinat, 2010 p.6). Reflexivity advocates critical self-reflection that encourages us to explore our social position(s), personal histories and the inherent biases that come with these (Vivanco, 2018). Cultural and social anthropologists seek to immerse themselves in the field as completely as possible through living with and learning from their local collaborators and participants in order to understand their ways of life from the inside out. They distinguish between an emic perspective (insider viewpoint) and an etic perspective (outsider viewpoint), all the while acknowledging that they can never be completely emic, due to their own cultural and personal preconceptions (Kottak, 2005; Lenkeit, 2004). They are encouraged to practice reflexivity, by constantly considering their own 
positionality, reflecting on how their individual cultural and personal baggage influences their research from conception to conclusion. They also consider how their presence and activities in the field affect the people and communities in which they work.

Reflexivity involves the cognitive process of turning back on ourselves (Nazaruk, 2011; Salzman, 2002). It is this act that enables us to recognise how our research is shaped and how we shape our research. The insights gleaned as this awareness develops enable us to understand how these factors influence and translate into our active and evolving practice. One of the simplest examples of this may involve reflecting on how certain questions are raised or responded to during ethnographic research, and how this can in turn influence how further communications are approached. To recognise and claim our positionality(ies), we need not view this process as though fulfilling a box-ticking exercise, but endeavour to intentionally engage with the way our positions influence our approach and analysis at every stage of inquiry (Guillemin \& Gillam, 2004). Like other ethical considerations, engaging with our positionality is not something that should only be examined at the beginning of a new project (Brittain et al., 2020). It is a practice that needs to be cultivated throughout. Through our interactions with other people, and their multispecies assemblages, we come to examine, question, and understand our own beliefs and positionality further. It is the attention of this process and the awareness of how it influences our approach, as well as its cyclical, iterative nature, that contributes to more thoughtful research and evenly distributed collaborations (Salzman, 2002). Multispecies approaches can provide ethnoprimatologists with insights into morethan-human worlds and offer broader ways of exploring how mutual ecologies are shaped (Fuentes, 2010; Jost Robinson \& Remis, 2018; Locke, 2018; Van Dooren et al., 2016). Consequently, consideration of our own more-than-human interactions, and their possible impact, needs to be integrated into our reflexive practice.

Reflexive practice is a multi-directional process. Not only does it involve the researcher reflecting on how their presence and particular approaches influence their work and those they interact with (prospective reflexivity), but it also includes examining how the research, and the researcher, is being affected throughout the project (retrospective reflexivity) (Attia \& Edge, 2017). These interactions constitute a continuous process of mutual exchange between researcher and research (Attia \& Edge, 2017). Anthropologists are encouraged from the beginning to keep a journal, apart from their field notes, that documents that latter form of reflexive practice, though researchers coming from natural science backgrounds may be unfamiliar with the benefits of this approach (England, 1994).

Diaries can incorporate a variety of elements. Much more than just a logging of activities, these accounts can provide a valuable learning tool and "repository for critical reflection" as the reseacher reviews entries written on how research was progressing while "in the thick of it" (Browne, 2013 p.421). Additionally, a personal field diary can act as an important cathartic device, allowing the researcher a safe outlet to document and process their fears, anxieties, and frustrations. This particularly holds true when carrying out fieldwork in areas experiencing political instability, unrest, and acts of violence, which also only serve to heighten the personal uncertainties one can generally experience while in the field (Browne, 2013). As 
many readers will recognise, primate conservation can often take place in unfamiliar or risky settings. Both Miranda Strubel (MS) and Claire Cardinal (CC) have experienced first-hand the benefits of keeping a reflective diary during difficult periods of their primate conservation work in Peru and Madagascar.

While inward or retrospective reflexivity may be uncomfortable to some researchers at first, we can vouch that this dimension of reflexive practice can prove insightful, particularly in regard to uncovering unconscious biases. For example, reflexive practice has particularly assisted MS in recognising when she is wearing different cognitive hats that reflect her different professional identities. While exploring interactions between humans and red kites (Milvus milvus) in southern England, MS found that many people believed that red kites were strictly carrion-eaters. It is true that they are predominantly carrion-feeders; however, being opportunistic scavengers, they also sometimes supplement their diet with small live prey. When research participants asked her about the red kites' diet, MS always informed them of all dietary "facts", but noticed she had a tendency to emphasize certain small prey (rodents and invertebrates) and neglected to include chicks in her list of examples, knowing that this could influence some people's perceptions of the birds, particularly those with concerns regarding small bird populations. In these small moments, MS became aware she was wearing her conservationist hat while in her role as anthropologist. While we often think of ethics in terms of the major concerns that need to be addressed at the beginning of a project, many of these dilemmas arise from the smaller ethical decisions we grapple with during our day-to-day interactions which can be referred to as microethics (Guillemin \& Gillam, 2004). If unprepared for these sorts of conflicts, "researchers risk making unethical decisions that can cause harm" (Brittain et al., 2020, p. 928).

One's different positionalities can sometimes be at odds. Researchers may sometimes feel conflicted between their values and responsibilities in relation to different stakeholder groups, for example participants, funders, other institutions, and collaborators (Brittain et al., 2020). These conflicts can sometimes be triggered by different values and responsibilities which one experiences in relation to both our human and non-human participants operating in a multispecies context, and the ethical and moral obligations one feels towards each. $\mathrm{CC}$ has experienced such a conflict of identities and responsibilities in her research on lemur hunting. When she and the local field team found lemur snares in the forest, her positionality as a conservationist inclined her to dismantle the traps to protect lemurs, whereas as a researcher she did not wish to portray herself as anti-hunting and risk alienating human research participants. Added to that, she felt that as an outsider it would be inappropriate to tell local people what to do in their forest. After reflection, she discussed the issues with the local field team, and one of the guides who also works as a forest ranger decided to destroy the snares. However, news travels quickly in the remote rural area where she works and local people would very likely associate $\mathrm{CC}$ with removal of the snares, despite her attempt to behave sensitively.

In contrast, Aimee Oxley (AO) and her team made an active decision from the start to dismantle traps (including illegal man traps and snare traps). They made this decision with permission from and the knowledge of the local village chairman and in line with the strategy of the nearby conservation project, with which AO was 
affiliated. The team removed traps that they found in the forest where they posed a significant risk to the life and limbs of chimpanzees (Pan troglodytes), which are protected. There was an ethical dilemma, in that local people would be prevented from trapping animals which it was perfectly legal to catch (e.g. edible rats) and the risk that this would alienate $\mathrm{AO}$ and her team from local people. However, in most cases those laying the traps appeared not to be from the village in which she and her team were based, and members of the local community supported this act.

Reflexivity is as pertinent in the natural sciences as it is in the social sciences (Hill \& McLennan, 2016; Malone et al., 2014; Montana et al., 2020). All of us wear a variety of identities that reflect the different roles we have in our lives. Here we focus particularly on our identity as researchers/practitioners and how our disciplinary training affects the way we carry out our research. It is important to emphasize that reflexivity and positionality are interrelated approaches. In considering their positions, researchers may frequently acknowledge their sex, gender, education, class, ethnicity etc. While these considerations are vital, positionality is much more than simply "a laundry list of identity markers" (Kohl \& McCutcheon, 2015, p.747). Engaging with our positionality requires us to delve beyond superficial acknowledgements and scrutinise the complex ways our positions matter in relation to those we interact with.

Each of us is shaped by a unique aggregation of knowledge and experiences, which influence the individual ways in which we approach our conservation research or practice. For example, when put on the spot, CC identifies herself as an ethnoprimatologist, which fits with her current research into lemur-human interactions. But this label poorly represents her diverse training in town planning, project management, animal welfare, captive management, and primate conservation, or the melange of professional and personal experiences and interests that affect how she approaches her work.

In a similar vein, MS has curated her training to develop herself as an interdisciplinary researcher, cultivating different skill sets and ways of knowing along the way. While she identifies as both an anthropologist and a conservationist, her education (in anthropology, environmental anthropology, biodiversity, and conservation) and multifarious research experiences have all contributed to her development as a human-wildlife researcher. Within certain academic contexts, MS sometimes feels constrained by disciplinary identity labels, often adopting one at the expense of another, or in an effort to combat this, identifying herself as an anthrozoologist. As the need for interdisciplinarity and the all-in-one researcher increases, as advocated by Welch-Devine et al. (2014), fruitful discussions around professional identify are likely to become more apparent, thereby necessitating the need for further reflexivity.

Practicing reflexivity can provide important insights (Boyce et al., 2021; England, 1994) and help us reveal the subtle ways in which we perform our identity (Kohl \& McCutcheon, 2015). Reflexive practice provides us with a strategy to better understand how our positions collectively influence us and to recognise the privileges they afford us while carrying out our work. For example, as researchers, we are generally the ones guiding research and setting the agenda. We also make decisions about which data gets collected, how it is interpreted, and ultimately how it is presented 
(Guillemin \& Gillam, 2004; Van Patter \& Blattner, 2020). Nevertheless, there is an element of fluidity to our positionalities (Montana et al., 2019), and our "social identity is also made and remade through the research process" (Rose, 1997, p.315). What is more, research preferences are likely to change over time (Peterson et al., 2010). In developing our awareness of power dynamics and discrepancies we also prevent against the marginalisation of other knowledges.

In common with other disciplines, current debates in primatology include the need to decolonise conservation (Cheyne et al., 2020; Rodrigues et al. this issue; Setchell, 2020; Waters et al., 2021). We are challenged to consider how our practices should change to ensure that differentials in power and opportunity no longer disenfranchise and exploit people in the countries in which we work, through cooption of land, knowledge, labour, or decision-making in the name of research and biodiversity conservation (Garland, 2008; Keller, 2009; Madden \& McQuinn, 2017; Rodrigues, 2020; Rubis, 2020; Rubis \& Theriault, 2019). Reflecting on our personal values and positionality is a first step in responding to this challenge.

Conservation research and action is often driven by urgency. Nevertheless, effective, mutually beneficial research is contingent on us taking the time to understand the context of our study sites. Many of the conservation contexts that researchers are involved in have complex histories. Moving towards decolonisation necessitates that we examine the historical and sociopolitical context of our research sites and recognise that earlier conservation initiatives may influence how participants receive us (Brittain et al., 2020). Failing to do this may jeopardise participants, researchers, and their relationships, particularly in areas where negative conservation narratives and legacies already exist (Brittain et al., 2020).

\section{Knowledge and Education}

Turning our reflective practice outwards to the communities in which we work leads us to consider how knowledge is interpreted and shared. We should beware of denigrating alternative worldviews or local knowledge about wildlife by ascribing the status of myth to them. Another pitfall is seizing on a particular cultural practice or belief that supports our conservation agenda, but ignoring other locally important values (Keller, 2009; Osterhoudt, 2018; Rubis, 2020). Instead, we should recognise that there are other forms of knowledge that are important and valuable, for example, traditional ecological knowledge, folkloric knowledge, knowledge around hunting and material culture, and experiential knowledge, to name a few (Anderson, 2011; Kutz \& Tomaselli, 2019). In fact, those are the very kinds of knowledge that we often seek to understand when conducting social science research. The emphasis should be on exploring the different types of knowledge that exist and appreciating that each are equally valuable, in addition to highlighting that research practitioners themselves come from different knowledge systems.

We have noticed that, while striving for engagement with local communities in relation to research or conservation programmes, primatologists often consciously or unconsciously do this with the implication that while they are listening they think they have more or superior knowledge. Furthermore, we have observed that many 
researchers often perceive that local people have a lack of knowledge or understanding about our study species, particularly if it does not include specific "facts" relating to the species' behavioural ecology. But what is knowledge? Researchers frequently only value scientific knowledge, and local knowledge can be disputed against the "facts" science provides (Boyce et al., 2021). In our work, we strive to recognise that other people's experiential knowledge is as valid and valuable as our biological knowledge, when discussing our focal species.

For example, in AO's PhD fieldwork, local people regularly offered knowledge about the behaviour and whereabouts of the chimpanzees she was studying in a human-modified environment in western Uganda. On one occasion, chimpanzees were reported to be seen further away than would make sense, according to what had been previously reported about chimpanzee daily path length in academic research. She followed up the report and, indeed, there were fresh nests and feeding traces several kilometres away from where the chimpanzees were seen the previous day or from any forest block. On reflection, AO's initial response was that this information was probably incorrect because it did not align to what she "knew" could be possible, but having the open-mindedness to welcome knowledge and information from local people allowed her to discover something fascinating about the ranging patterns of the chimpanzee community she was studying.

The devaluation of native people's knowledge links with an outdated (but very commonly used) top-down approach imparted when conservation education programmes seek to superimpose Euro-western forms of understanding above native knowledge (Bettinger \& Leighty, 2021; Rubis, 2020; West et al., 2006). Undoubtedly this is done with the best intentions, for example "If only local people knew what we know, they would realise how important this primate/habitat is and stop their harmful practices." But education frequently echoes a colonialist narrative and implies that certain types of knowledge are more valid than others. Not only is this attitude disrespectful, but there is a danger that education given without full understanding of the local cultural and social context may be offensive, ignored as worthless, or potentially culturally destructive (Bettinger et al., 2021; Bettinger \& Leighty, 2021; Wallis \& Lonsdorf, 2010). Such an approach can be counter-productive, in that local people may become alienated or unwilling to engage with conservation efforts. A more productive approach is knowledge sharing. Through ethnoprimatological approaches we can share what we know or have learnt through our research, but accepting local knowledge is equally important.

Indigenous, traditional, and local knowledge can provide valuable contributions to conservation efforts, particularly at fine grain, spatial, and temporal scales (Tengö et al., 2014). Three ethnoprimatological studies illustrate the importance and value of incorporating local people's knowledges and viewpoints in primate conservation. Dore's study (2018) of the political ecology of "the monkey problem" in St Kitts explores the viewpoints of local Kittitian farmers towards green monkeys (Chlorocebus sabeus) and reveals the historical and contemporary issues associated with land, power, and economy that have influenced their perspectives. Whilst conserving the introduced monkeys is not the issue, she highlights a disconnect between the farmers' need to make a living and the changing pressures that external actors exert on debates about how to deal with the monkeys. Dore's long-term engagement with 
farmers and other stakeholders has helped her to understand the context in which the farmers' narratives about monkeys are situated and to apply this understanding through her participation in multi-stakeholder monkey management discussions (Dore, 2017, 2018).

The disconnect between local and global viewpoints about land is also highlighted in Keller's research $(2008,2009)$ in Masoala, Madagascar. By regarding the forest as a habitat to be preserved in order to protect or enhance biodiversity, conservationists can be said to hold an "ethos of static equilibrium" (Keller, 2008, p.651). In contrast, local people's understandings stem from an "ethos of growth", whereby land provides the means for a successful life based on producing many descendants to extend one's kin group (which includes one's ancestors as well as descendants) (Keller, 2008, p.652). The gazetting of land as a Protected Area causes local people to feel "defeated in the purpose of life" according to their worldview (Keller, 2008, p.659). In this context, Keller cautions that the conservation approach of educating local people about the need to cease forest conversion to agriculture and reduce the number of children they had would be ineffective because it conflicts with their fundamental values about growth and the meaning of success (Keller, 2008).

In their research into the ethnoprimatology of the Waorani people of the Ecuadorian Amazon, Papworth and her colleagues wanted to understand the cultural importance of local nonhuman primate species in Waorani society and how this influenced people's hunting practices (Papworth et al., 2013). They found that the ways in which Waorani people grouped and conceptualised animals differed from Euro-western taxonomy, and that among a variety of primate and non-primate animal species only the woolly monkey (Lagothrix poeppigii) was distinguished as culturally important. What these articles have in common is their emphasis on valuing the knowledge systems of local people (not simply to find out their response to a particular conservation initiative), by trying to understand the deeply rooted cultural perspectives and experiences that have a bearing on their relationships with primates and the places where they interact. These examples also highlight the importance of not imposing Euro-western scientific viewpoints when shaping conservation initiatives.

Anthropological endeavours have made valuable contributions to understanding how different ontological lenses shape people's experience of their surroundings. In Euro-western philosophies, environmental ideology generally separates nature from culture (Caillon et al.2017; Vining et al., 2008). However, dichotomies separating humans from nature do not reflect the worldviews held by many other cultural groups (Brightman, 2017; Descola, 2013). Whilst this can mean that the goals of different actors may clash, in some circumstances, even when the worldviews of local/Indigenous groups differ, there may be points where their objectives coincide (Berkes, 2004). Sacred groves and other sacred sites provide an example highlighting how local beliefs and safeguards and conservation initiatives can be complementary, thereby providing a bridge between these knowledge systems. They are sometimes designated as community-conserved areas, and are well-documented in many different parts of the world (Mallarach, 2008; Parthasarathy \& Naveen Babu, 2019). Sacred sites are upheld by the adherence to socially bound local taboos, sanctions, and belief systems, and tied closely to the environment and the natural resources that 
people depend on over a long period of time (Farooquee et al., 2004; Parthasarathy \& Naveen Babu, 2019).

In their work comparing tree, bird and macrofungi species across forest reserves, sacred groves and coffee plantations in the Western Ghats, India, researchers found that sacred groves contained a distinct assemblage of endemic and threatened species (Bhagwat et al., 2005). Despite variations between the three habitats, Bhagwat et al. (2005) suggest that, due to the contiguous nature of the tree cover, these differences might not be perceptible to wildlife, thereby providing greater connectivity opportunities throughout a mosaic landscape. As such, sacred sites can potentially benefit nonhuman species by providing refugia or enhancing connectivity.

Sadly, many of these traditional methods of sustainability and conservation are now in decline, as multiple factors threaten them, including transition to market economies, developmental interventions, rural-urban migration, and decreases in intergenerational knowledge transmission (Farooquee et al., 2004; Parthasarathy \& Naveen Babu, 2019; Singh et al., 2017). With this decline comes a loss of local ecological knowledge and the social mores that uphold the preservation and sustainable harvesting of forest resources, which may result in more pressure being put on these resources (Baker et al., 2014). In examples from sacred forests in southeastern Nigeria and southeastern Madagascar respectively, conservationists have collaborated with local people to find concordance between local desires to uphold social and cultural values in the face of changing values and external pressures, and conservationists' aims to protect local primate species (Baker et al., 2014; Gardner et al., 2008).

Collaboration is integral to knowledge-sharing, but the level of participation of local stakeholders should always be context- and project-specific. There are various modes in which local people might participate in conservation, including: 1) engaging in discussion and feedback, 2) generating shared analysis and interpretation of data, and 3) participating in agenda setting (Bieler et al., 2021). Knowledge coproduction extends the participation of local or Indigenous people into the second and third modes, so that they are collaborators at every stage of the project process, rather than simply invited to the table after key decisions have been made. Co-production has been defined as "iterative and collaborative processes involving diverse types of expertise, knowledge, and actors to produce context-specific knowledge and pathways towards a [specific goal]" (Nörstrum et al., 2020, p.183).

In contrast to scientific knowledge, local or traditional knowledge is usually experiential, related to local resource use, and often based on observations extending over long time periods (Berkes, 2004; Moller et al., 2004). Triangulating data from multiple evidence bases across knowledge systems can provide a way of examining Indigenous, local, and scientific knowledge systems in parallel and revealing complementarities that serve to provide a richer, more holistic knowledge base from which to work (Sterling et al., 2017; Tengö et al., 2014). The synthesis of different knowledges enables cross-fertilisations and integrations that can produce a new, enriched picture of the particular problem or issue (Berkes, 2004; Moller et al., 2004; Moore \& Hauser, 2019; Tengö et al., 2014). Collaborative approaches are grounded in the understanding that diverse knowledge systems are equally important and valid. Although contradictions may also arise between different ways of 
knowing, they can also provide additional insights and a better overall understanding of the phenomena under investigation. If this bridging of knowledges were to be taken up by diverse knowledge representatives, and founded on mutual recognition of legitimacy, power, and ways of knowing/understanding the world, collaboration may flow more freely (Tengö et al., 2014).

Whilst most primatologists focus on mode 1 methodologies (engaging in discussion and feedback) with which they are most familiar, case studies from the wider conservation literature demonstrate the practical value of co-production to bridge local and scientific knowledges. Examples demonstrating how knowledge co-production involving ecologists and Indigenous peoples have been used in applied conservation to: assess and monitor the health of muskoxen (Ovibos moschatus wardi) and caribou (Rangifer tarandus) populations in Nunavut, Canada (Tomaselli et al., 2018), monitor populations and agree on sustainable harvesting levels of sooty shearwater (Puffinus griseus) in New Zealand (Moller et al., 2004), and improve longitudinal monitoring of sea-ice dynamics and marine mammal health and ecology in the Alaskan Arctic. The latter contributed to tracking of ecosystem variability and supporting food security for Indigenous whale-hunting communities (Moore \& Hauser, 2019). Whilst these projects have not been without disagreements among the various actors, they demonstrate the important roles local people can and could have in conservation monitoring and management, particularly in light of the fact that funding is often stretched thin during this phase of research (Fernandez-Gimenez et al., 2006; Moore \& Hauser, 2019).

The coproduction of ecological knowledge using participatory methods and respecting multiple ways of knowing can be beneficial to research and conservation (Setchell et al., 2017), but what is done with this knowledge is also important and germane to the decolonisation debate. Latulippe and Klenk (2020) argue that Indigenous knowledge is inseparable from Indigenous governance. Knowledge should not be considered merely as data to be extracted and used to inform decision-making and actions by outside organisations. Instead, co-production of knowledge should be empowering to the local communities and supportive of societal goals (Kutz \& Tomaselli, 2019; Turnhout et al., 2020). That is not to say that we should abjure our own knowledge. As researchers and conservationists, we have a responsibility to offer our knowledge in support of local people and also a responsibility to treat knowledge that is given to us with respect and integrity.

\section{Introducing the Concept of Resilience When Evaluating Success}

We consider that the ultimate goal of a successful primate conservation programme is for non-human primates and local people to be thriving, for the habitat to be stable and sufficient to meet their needs, and for this social-ecological situation to be sustainable over time (Estrada et al., 2017; Hill, 2002; Lee, 2010; Riley, 2013; Waters et al., 2021). Achieving shared understanding with local people about the issues and potential solutions relating to a primate conservation problem requires not only personnel with appropriate anthropological/qualitative training but also long-term commitment. Typically, research or conservation proposals identify the outputs or 
outcomes against which success will be measured. It is important to understand the difference, as they often become muddled: outputs are measurable activities or products (such as survey effort or the number of people participating in training or outreach initiatives); outcomes are the changes that occur as a consequence of the intervention (measured against indicators such as species population growth or aspects of human behavioural change). Whilst it is reasonable to identify short or mediumterm outputs as a measure of success in research projects, in conservation, achieving biodiversity or habitat outcomes is a long-term enterprise that may be subject to changing pressures over time.

We consider the four categories to assess success in conservation projects suggested by Brooks et al., 2006 (ecological, economic, behavioural and attitudinal) to encompass a large proportion of the areas needed to assess conservation success, but we also propose a fifth domain: resilience.

"Resilience is the capacity of a system to absorb disturbance and reorganize while undergoing change so as to still retain essentially the same function, structure, identity, and feedbacks" (Walker et al., 2004, p.2)

Whilst the concept of resilience was originally conceived in relation to ecological systems (Hollin, 1973), it can also be discussed in terms of human social systems (Berkes \& Turner, 2006; Walker et al., 2004) and cultures (Pretty et al., 2009). The interconnections between people and nature are emphasised in the concepts of biocultural diversity (Maffi, 2005) and social-ecological resilience (Walker et al., 2016).

Biocultural approaches recognise the linkages between biological diversity and human cultural diversity and the common threats they face (Pretty et al., 2009; Sterling et al., 2017). The extensive geographic co-occurrence between biodiversity hotspots/high biodiversity wildernesses and linguistic diversity (as a proxy for cultural diversity) suggests that conserving both biodiversity and human cultural richness is likely to be beneficial for human and nonhuman species alike (Gorenflo et al., 2012).

"In the same way that biological diversity underpins the resilience of natural systems, cultural diversity has the capacity to increase the resilience of social systems" (Pretty et al., 2009, p.101).

As such, resilience provides a relevant and useful criterion in ethnoprimatology and conservation. Resilience is founded on the assumption that social-ecological systems are dynamic, and it contributes to sustainability by providing the capacity for adaptation or transformation in the system as circumstances change (Berkes \& Turner, 2006). In this sense, in a resilient system we are not striving for constant stasis, but instead for the adaptive capacity to retain or recover stability in the face of disturbance and uncertainties that may arise from emerging pressures. This depends on creating a mindset where actors in the conservation process and governance mechanisms are open and responsive to adaptation, rather than adhering doggedly to fixed pathways that have been set at the beginning of a project (Biggs et al., 2012) or nostalgia for a landscape that no longer exists. 
So how do we go about building in resilience to primate conservation programmes? Interactions between nature and human culture are manifested in a society's worldviews, knowledge, language, livelihoods, norms, and institutions (Pretty et al., 2009), so an integrated approach is essential for maintaining the well-being and resilience of both biodiversity and local communities, and thereby the sustainability of conservation programmes (Caillon et al., 2017; Gavin et al., 2015). Biggs et al. (2012) propose seven interconnected principles for enhancing resilience of ecosystem services. Table I summarises these principles and highlights their utility for conservation projects. We wish to promote these principles as a theoretical framework applicable to enhancing the resilience of primate conservation programmes, based on our experience and observations of projects, both within and outside the field of conservation.

The principles are organised into two types: 1-3 are properties to be managed and 4-7 are attributes to be incorporated into governance systems. Evidently, every conservation case is unique and requires a contextually appropriate approach. To illustrate how application of the framework could assist primate conservation, we can consider a hypothetical (but common) scenario where a nonhuman primate population is under threat from habitat fragmentation due to agricultural expansion by local farmers. One only has to look at the negative effects that disruptions associated with the COVID-19 pandemic have wrought on protection of primate populations, continuity of conservation and research programmes, and available funding (Evans et al., 2020; Lappan et al., 2020) to recognise the importance of maintaining diversity and redundancy (contingency reserves or compensatory capacity) in supporting resilience (principle 1). In our hypothetical example, we might consider how to maintain diversity of habitats, tree species, livelihoods, funding streams, and ideas (principle 1), all the time recognising the interconnectedness of the human-nonhuman primate spheres (principle 4) and ensuring that there is sufficient capacity and flexibility for both to cope in the event of future shocks (principle 1). We could consider climate change as an example of a slow variable, where as yet uncertain impacts on habitats and resources may loom on the horizon. Collective scenario planning (Peterson et $a l ., 2003$ ) could support preparedness for a range of potential future impacts on ecosystems, homes, crops, and infrastructure arising from changes in rainfall patterns and temperatures (principle 3).

As primatologists, readers may recognise that, in our hypothetical scenario, connecting habitat patches could be a way of expanding nonhuman primate social networks and enabling genetic diversity to improve the resilience of a population to stochastic events. This provides a useful analogy which can be applied to governance in conservation. In a programme designed to enhance resilience, the emphasis would be on establishing inclusive, consensual, multi-level governance (principles 6 and 7) to strengthen connectivity of stakeholder networks (principle 2) and promote knowledge sharing, trust, and collective action (principle 5). This would facilitate the grounding of potential conservation pathways in their wider spatial, social, economic, political, and cultural contexts, taking into account local and broader-thanlocal perspectives. Recognition of the dynamic nature of the social-ecological system stimulates an adaptive ethos that supports continuous re-evaluation of issues, potential solutions, and change pathways (principle 4). 


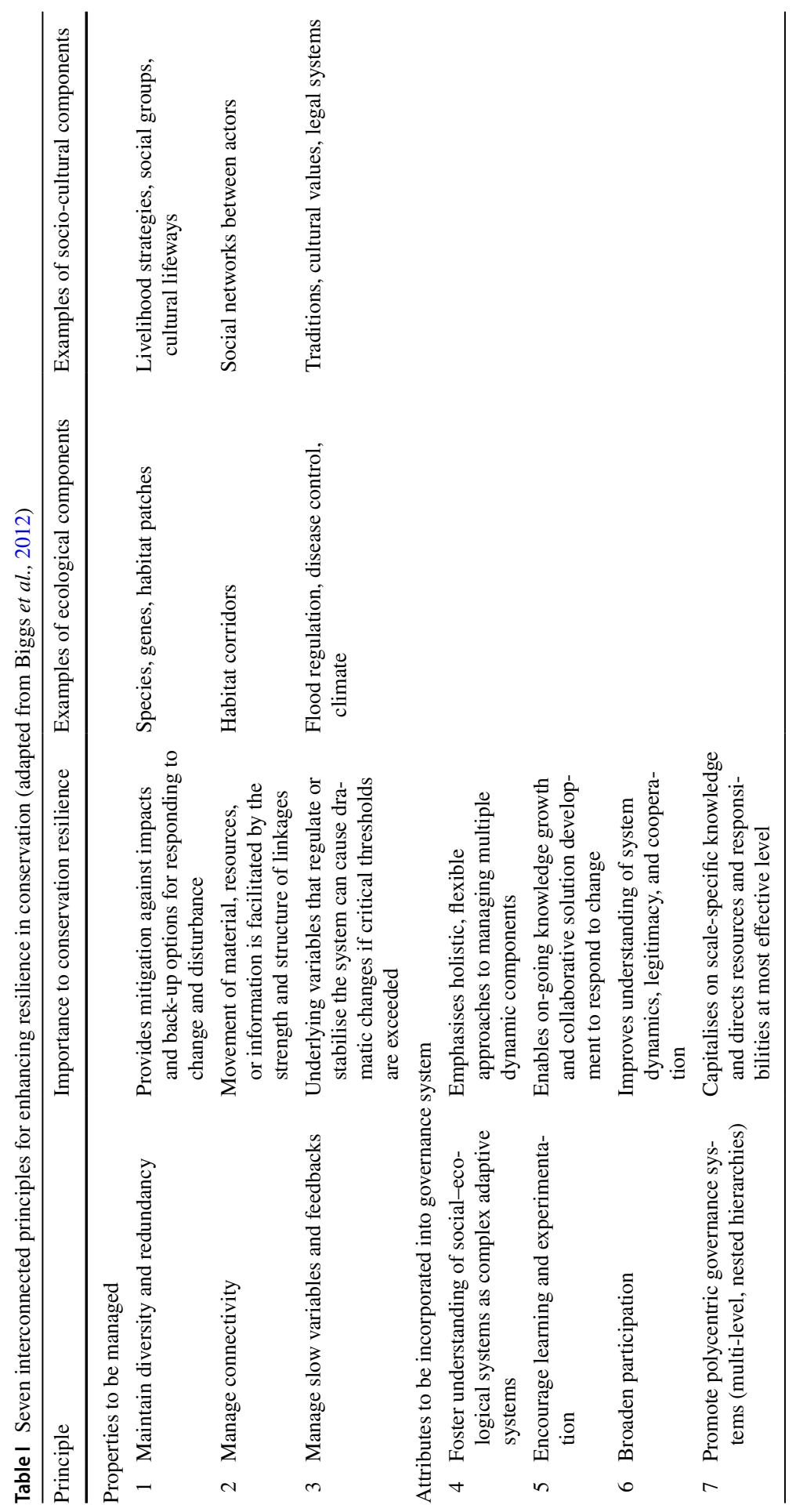


Enabling the seven principles for enhancing resilience depends on generating holistic knowledge of the problems and issues within their context, and cooperation among stakeholders in exploring, implementing, and monitoring solutions. In the last two decades it has become increasingly recognised that community participation is essential to maximise the sustainability of conservation programmes, as well as for reasons of equity and social justice (Brosius, 2004; Hutton et al., 2005; IUCN, 2003). However, participation in itself is not an outcome - it is an input into the project. Achieving conservation resilience depends on genuine multi-stakeholder engagement to enable a shared understanding of all the various perspectives of the problem and a shared vision of goals, change pathways, and responsibilities (O'Connell et al., 2016; Walker et al., 2016). Many projects have failed to achieve their biodiversity conservation goals because the goals are those of external actors, rather than encompassing the objectives of local people. The resilience approach requires the capacity for continuous sharing of ideas, testing options, learning, and adaptation to be integral to the implementation process and governance structures (Biggs et al., 2012; Walker et al., 2016). This supports the integration of actors' multiple knowledges, values, and aspirations for resource and landscape management (Caillon et al., 2017).

In their discussion of Conservation Conflict Transformation, Madden and McQuinn (2017) postulate that whereas most conservation and development efforts focus on meeting the basic physiological and security needs of people, addressing their social and psychological needs is equally important. These include empowerment, recognition, identity, and control over decisions. Psychological research provides useful insights into the nature of human motivations, which can enhance our understanding of these social and psychological needs. Self-determination theory identifies two kinds of human motivation, namely intrinsic (arising from within an individual) and extrinsic (arising from outside the individual), with intrinsic motivation found to generate enhanced performance, persistence, creativity, self-esteem, and general well-being (Ryan \& Deci, 2000). Three psychological factors are necessary to facilitate intrinsic motivation: the need for competence, relatedness, and autonomy (Ryan \& Deci, 2000). These factors dovetail closely with the four social and psychological needs identified by Madden and McQuinn (2017). In their exploration of the links between self-determination theory and conservation success, Cetas and Yasué (2016) found that community-conservation projects that fostered conditions for intrinsic motivation were more likely to succeed in meeting ecological, social, or economic goals (both separately or in combination). Their research demonstrated that generating intrinsic or extrinsic motivation was not predicated upon the particular kind of conservation instrument used (for example, community education, direct payments, development schemes, regulation), but instead depended more on the way in which it was offered in the particular social context to maximise feelings of self-determination and autonomy (Cetas \& Yasué, 2016).

If we are sincere about ensuring that local participation in projects is genuine and meaningful, we have a responsibility to ensure that engagement and consultation are not one-sided information-giving or just superficial exercises to demonstrate that community interests have been considered. We should recognise that Indigenous or other local people are not simply stakeholders in their homelands, and that there is 
a difference between participation and autonomy (Latulippe \& Klenk, 2020). In this context, we have to be prepared to accept conservation solutions and compromises that do not necessarily meet all of our own preferred outcomes. As Madden and McQuinn (2017) point out, conservationists fear that if they relinquish control over conservation they will have to compromise over conserving species and habitats. But, in fact, evidence shows that cooperative working and consensus-building generate trust and understanding of each other's motivations that can lead to better conservation and societal outcomes (Madden \& McQuinn, 2017).

In trying to foster consensus and collaboration between multiple stakeholders, it is important to acknowledge that as primatological researchers or conservation practitioners we $d o$ have an opinion (recognising our positionality). Even if we come with intended neutrality and open-mindedness to understand local peoples' viewpoints, we actually have an agenda, a pre-existing goal that we wish to see realised (for example, saving a particular species or stopping hunting/deforestation), and which is probably written into our research or funding proposal.

We have noticed that our positionality is often portrayed without words. Simply because we are studying a particular primate, local people may assume that our over-riding concern is for the conservation or welfare of that species. This can affect how local people regard us, even if we have best intentions to approach from a neutral position. This raises important ethical issues, as it constrains our ability to both act neutrally and to express our aspirations freely. By reflecting on our own positionality and respecting those of others, we can move towards acknowledging the conflicts between the responsibilities we hold towards our various collaborators, including research participants, institutions, and funders (Brittain et al., 2020) as well as our nonhuman primate subjects. Regarding ourselves as one voice among multiple stakeholders is likely to enable a more equitable and collaborative approach towards primate conservation initiatives that will ultimately be more empowering to all concerned.

\section{Concluding Remarks}

So where in all this is a future role for primatologists? With researchers and practitioners increasingly bridging the social-ecological gap, this is a unique opportunity to support genuine bottom-up and community-led conservation. Valuing and integrating multiple ways of knowing promotes deeper understanding and more viable conservation solutions, in addition to supporting genuine collaboration, respect, and trust. Understanding the complex socio-cultural, historical, and political contexts in which we work, as well as how different actor networks inter-relate (Jepson et al., 2011), is also essential. Reflexive engagement within our more-than-human research environments can assist with this, and enables us to locate our inherent biases and privileges, so as to better understand power dynamics and navigate ethical dilemmas. Moving beyond formalised communications and reflecting on the everyday talk we share with those with whom we interact can also provide further insights (Kohl \& McCutcheon, 2015). In parallel, we also need to cultivate and nurture this type of sharing within academia and the wider primatology profession (Brittain et 
al., 2020). Sharing our experiences of pitfalls, as well as successes, within primatology can facilitate learning and better equip conservation practice.

In taking a biosocial approach, researchers can better investigate what would make people feel intrinsically motivated (i.e. by asking them what they want to see happen). We believe further study in this area would enhance future research. By spending time getting to know people, and the multispecies communities in which they/we are embedded, ethnoprimatologists can incorporate data on people's beliefs and perceptions as well as other important aspects of the bio-social domain (Dore, 2017, 2018; Hardin \& Remis, 2006; Jost Robinson \& Remis, 2018; Waters et al., 2020). This can facilitate strategies that will foster intrinsic motivation and build resilience, rather than perpetuating more top-down approaches (extrinsic motivation).

We conclude by reiterating the uncomfortable idea that perhaps conservation solutions may not match our pre-existing ideas of success, and the end result of consensus-building will be somewhere between them and what local people want and need. In much the same way as we have previously had to admit that there are no pristine habitats, we should also accept that there are no perfect conservation solutions. The solutions we do find need to fit within the parameters of the existing practices and beliefs of the local people. We can only achieve this by realising our own positionality and having the flexibility to re-define our measures of success.

Acknowledgements We thank the editors of this Special Issue, Giuseppe Donati, Catherine M Hill, and Aimee Oxley, for inviting us to contribute this article, and Elena Bersacola for her thoughts at the beginning. Many thanks to the two anonymous reviewers and the Editor-in-Chief for their helpful and generous comments, which have greatly improved this paper.

Author contributions AO originally formulated the idea; MS, CC, and AO developed the content; CC and MS wrote the manuscript.

\section{Declarations}

Conflict of Interest The authors declare that they have no conflict of interest.

\section{References}

Adams, W. M. (2007). Thinking like a human: social science and the two cultures problem. Oryx, 41, 275-276. https://doi.org/10.1017/S0030605307004131.

Akçakaya, H. R., Bennet, E. L., Brooks, T. M., Grace, M. K., Heath, A., et al (2018). Quantifying species recovery and conservation success to develop an IUCN Green List of species. Conservation Biology, 32, 1128-1138. https://doi.org/10.1111/cobi.13112.

Anderson, E. N. (2011). Ethnobiology: Overview of a growing field. In E. N. Anderson, D. Pearsall, E. Hunn, \& N. Turner (Eds.), Ethnobiology (pp. 1-14). John Wiley and Sons Inc..

Attia, M., \& Edge, J. (2017). Be(com) ing a reflexive researcher: a developmental approach to research methodology. Open Review of Educational Research, 4, 33-45. https://doi.org/10.1080/23265507. 2017.1300068 .

Baker, L. R., Olubode, O. S., Tanimola, A. A., \& Garshells, D. L. (2014). Role of local culture, religion and human attitudes in the conservation of sacred populations of a threatened 'pest' species. Biodiversity Conservation, 23, 1895-1909. https://doi.org/10.1007/s10531-014-0694-6. 
Bennett, N. J., Roth, R., Klain, S. C., Chan, K. M., Clark, D. A., et al (2016). Mainstreaming the social sciences in conservation. Conservation Biology, 31, 56-66. https://doi.org/10.1111/cobi.12788.

Bennett, N. J., Roth, R., Klain, S. C., Chan, K., Christie, P., et al (2017). Conservation social science: understanding and integrating human dimensions to improve conservation. Biological Conservation, 205, 93-108. https://doi.org/10.1016/j.biocon.2016.10.006.

Berkes, F. (2004). Rethinking community-based conservation. Conservation Biology, 18, 621-630. https://doi.org/10.1111/j.1523-1739.2004.00077.x.

Berkes, F., \& Turner, N. J. (2006). Learning and the evolution of conservation practice for socialecological system resilience. Human Ecology, 34(4), 479-494. https://doi.org/10.1007/ s10745-006-9008-2.

Bettinger, T., \& Leighty, K. (2021). The evolution of conservation education and its role in saving apes in Africa. American Journal of Primatology, 83, e23203. https://doi.org/10.1002/ajp.23203.

Bettinger, T., Cox, D., Kuhar, C., \& Leighty, K. (2021). Human engagement and great ape conservation in Africa. American Journal of Primatology, 83, e23216. https://doi.org/10.1002/ajp.23216.

Bhagwat, S. A., Kushalappa, C. G., Williams, P. H., \& Brown, D. B. (2005). The role of informal protected areas in maintaining biodiversity in the Western Ghats of India. Ecology and Society, 10, 8. https://doi.org/10.5751/es-01285-100108.

Bieler, P., Bister, M. D., Hauer, J., \& von Peter, S. (2021). Distributing reflexivity through co-laborative ethnography. Journal of Contemporary Ethnography, 50, 77-88. https://doi.org/10.1177/08912 41620968271.

Biggs, R., Schlütter, M., Biggs, D., Bohensky, E. L., BurnSilver, S., et al (2012). Toward principles for enhancing the resilience of ecosystem services. Annual Review of Environment and Resources, 37, 421-448. https://doi.org/10.1146/annurev-environ-051211-123836.

Boyce, P., Bhattacharyya, J., \& Linklater, W. (2021). The need for formal reflexivity in conservation science. Conservation Biology, 1-9. https://doi.org/10.1111/cobi.13840.

Brightman, M. (2017). Savage values: conservation and personhood in southern Suriname. In C. M. Hill, A. D. Webber, \& N. E. C. Priston (Eds.), Understanding conflicts about wildlife: A biosocial approach (pp. 95-106). Berghahn Books.

Brittain, S., Ibbett, H., de Lange, E., Dorward, L., Hoyte, S., et al (2020). Ethical considerations when conservation research involves people. Conservation Biology, 34, 925-933. https://doi.org/10. 1111/cobi.13464.

Brooks, J. S., Franzen, M. A., Holmes, C. M., Grote, M. N., \& Mulder, M. B. (2006). Hypotheses for the success of different conservation strategies. Conservation Biology, 20, 1528-1538. https://doi.org/ $10.1111 /$ j.1523-1739.2006.00506.

Brosius, J. P. (2004). Indigenous peoples and protected areas at the World Parks Congress. Conservation Biology, 18, 609-612. https://doi.org/10.1111/j.1523-1739.2004.01834.x.

Browne, B. C. (2013). Recording the personal: The benefits of maintaining research diaries for documenting the emotional and practical challenges of fieldwork in unfamiliar settings. International Journal of Qualitative Methods, 12, 420-435. https://doi.org/10.1177/160940691301200121.

Caillon, S., Cullman, G., Verschuuren, B., \& Sterling, E. J. (2017). Moving beyond the human-nature dichotomy through biocultural approaches: including ecological well-being in resilience indicators. Ecology and Society, 22, 27. https://doi.org/10.5751/es-09746-220427.

Campbell, L. M. (2005). Obstacles to interdisciplinary research. Conservation Biology, 19, 574-577. https://doi.org/10.1111/j.1523-1739.2005.00058.x.

Cetas, E. R., \& Yasué, M. (2016). A systematic review of motivational values and conservation success in and around protected areas. Conservation Biology, 31, 203-212. https://doi.org/10.1111/cobi. 12770.

Cheyne, S., Corduant-Andriantsaralaza, S., Rodrigues, M., Rubis, J., Setchell, J. \& Waters, S. (2020). Decolonising Conservation [Webinar]. IUCN-SSC Primate Specialist Group-Section for HumanPrimate Interactions. Retrieved from: https://human-primate-interactions.org/decolonising-conse rvation/. Accessed 10 January 2021.

Collins, P., \& Gallinat, A. (2010). The ethnographic self as resource: An introduction. In P. Collins \& A. Gallinat (Eds.), The ethnographic self as resource: Writing memory and experience into ethnography (pp. 1-24). Berghahn Books.

Descola, P. (2013). Beyond Nature and Culture. The University of Chicago Press.

Dominy, M. D. (2018). Reflexivity. In F. Callan (Ed.), The International Encyclopedia of Anthropology (pp. 1-3). John Wiley \& Sons, Ltd. https://doi.org/10.1002/9781118924396.wbiea1976. 
Dore, K. M. (2017). Navigating the methodological landscape: ethnographic data expose the nuances of "the monkey problem" in St Kitts, West Indies. In K. M. Dore, E. P. Riley, \& A. Fuentes (Eds.), Ethnoprimatology: A practical guide to research at the human-primate interface (pp. 219-231). Cambridge University Press.

Dore, K. M. (2018). Ethnoprimatology without conservation: the political ecology of farmer-green monkey (Chlorocebus sabaeus) relations in St Kitts, West Indies. International Journal of Primatology, 39, 918-944. https://doi.org/10.1007/s10764-018-0043-9.

Dore, K. M., Radford, L., Alexander, S., \& Waters, S. (2018). Ethnographic approaches in primatology. Folia Primatologica, 89, 5-12. https://doi.org/10.1159/isbn.978-3-318-06346-2.

Engelke, M. (2017). Think like an anthropologist. Penguin Random House.

England, K. V. L. (1994). Getting personal: reflexivity, positionality and feminist research. Professional Geographer, 46, 80-89. https://doi.org/10.1111/j.0033-0124.1994.00080.x.

Eriksen, T. H. (2004). What is Anthropology? Pluto Press.

Estrada, A., Garber, P. A. Rylands, A. B. ... and Li, B. (2017). Impending extinction crisis of the world's primates: why primates matter. Science Advances, 3(1), 1-16. https://doi.org/10.1126/sciadv.16009 46.

Evans, K. L., Ewan, J. G., Guillera-Arroita, G., Johnson, J. A., Penteriani, V., et al (2020). Conservation in the maelstrom of Covid-19 - a call to action to solve the challenges, exploit opportunities and prepare for the next pandemic. Animal Conservation, 23, 235-238. https://doi.org/10.1111/acv. 12601.

Farooquee, N. A., Majila, B. S., \& Kala, C. P. (2004). Indigenous knowledge systems and sustainable management of natural resources in a high altitude society in Kumaun Himalaya, India. Journal of Human Ecology, 16, 33-42. https://doi.org/10.1080/09709274.2004.11905713.

Fernandez-Gimenez, M. E., Huntington, H. P., \& Frost, K. J. (2006). Integration or co-optation? Traditional knowledge and science in the Alaska Beluga Whale Committee. Environmental Conservation, 33, 1-10. https://doi.org/10.1017/S0376892906003420.

Fox, H. E., Christian, C., Nordby, J. C., Pergams, O. R. W., Peterson, G. D., \& Pyke, C. R. (2006). Perceived barriers to integrating social science \& conservation. Conservation Biology, 20, 1817-1820. https://doi.org/10.1111/j.1523-1739.2006.00598.x.

Fuentes, A. (2007). Monkey and human interconnections: the wild, the captive, and the in-between. In R. Cassidy \& M. Mullin (Eds.), Where the wild things are now (pp. 123-145). Routledge.

Fuentes, A. (2010). Naturalcultural encounters in Bali: Monkeys, temples, tourists, and ethnoprimatology. Cultural Anthropology, 25, 600-624. https://doi.org/10.1111/j.1548-1360.2010.01071.x.

Fuentes, A. (2012). Ethnoprimatology and the anthropology of the human-primate interface. Annual Review of Anthropology, 41, 101-117. https://doi.org/10.1146/annurev-anthro-092611-145808.

Gardner, C. J., Ferguson, B., Rebara, F., \& Ratsifandrihamanana, A. N. (2008). Integrating traditional values and management regimes into Madagascar's expanded protected area system: the case of Ankodida. In J.-M. Mallarach (Ed.), Protected landscapes and cultural and spiritual values (pp. 92-103). IUCN, GTZ and Obra Social de Caixa Catalunya: Kasparek Verlag.

Garland, E. (2008). The elephant in the room: confronting the colonial character of wildlife conservation in Africa. African Studies Review, 51, 51-74. https://doi.org/10.1353/arw.0.0095.

Gavin, M. C., McCarter, J., Mead, A., Berkes, F., Stepp, J. R., et al (2015). Defining biocultural approaches to conservation. Trends in Ecology and Evolution, 30, 140-145. https://doi.org/10. 1016/j.tree.2014.12.005.

Gorenflo, L. J., Romaine, S., Mittermeier, R. A., \& Walker-Painemilla, K. (2012). Co-occurrence of linguistic and biological diversity in biodiversity hotspots and high biodiversity wilderness areas. Proceedings of the National Academy of Sciences, 109, 8032-8037. https://doi.org/10.1073/pnas. 1117511109.

Guillemin, M., \& Gillam, L. (2004). Ethics, reflexivity and "ethically important moments" in research. Qualitative Inquiry, 10, 261-280. https://doi.org/10.1177/1077800403262360.

Hackett, E. J., \& Rhoten, D. (2009). The snowbird charrette: integrative interdisciplinary collaboration in environmental research design. Minerva, 47, 407-440. https://doi.org/10.1007/s11024-009-9136-0.

Halpern, B. S., Klein, C. J., Brown, C. J., Beger, M., Grantham, H. S., et al (2013). Achieving the triple bottom line in the face of inherent trade-offs among social equity, economic return, and conservation. Proceedings of the National Academy of Sciences, 110(15), 6229-6234. https://doi.org/10. 1073/pnas.1217689110.

Haraway, D. J. (1988). Situated knowledges: The science question in feminism and the privilege of partial perspective. Feminist Studies, 14, 575-599. https://doi.org/10.2307/3178066. 
Hardin, R., \& Remis, M. J. (2006). Biological and cultural anthropology of a changing tropical forest: a fruitful collaboration across subfields. American Anthropologist, 108(2), 275-285. https://doi.org/ 10.1525/aa.2006.108.2.273.

Hill, C. M. (2002). Primate conservation and local communities: ethical issues and debates. American Anthropologist, 104(4), 1184-1194. https://doi.org/10.1525/aa.2002.104.4.1184.

Hill, C. M., \& McLennan, M. R. (2016). The primatologist as social actor. Etnográfica, 2, 668-671. https://doi.org/10.4000/etnografica.4771.

Hollin, C. S. (1973). Resilience and stability of ecological systems. Annual Review of Ecology and Systematics, 4, 1-23. https://doi.org/10.1146/annurev.es.04.110173.000245.

Howe, C., \& Milner-Gulland, E. J. (2012). Evaluating indices of conservation success: a comparative analysis of outcome- and output-based indices. Animal Conservation, 15, 217-226. https://doi.org/ 10.1111/j.1469-1795.2011.00516.x.

Hutton, J., Adams, W. M., \& Murombedzi, J. C. (2005). Back to the barriers? Changing narratives in biodiversity conservation. Forum for Development Studies, 32, 341-370. https://doi.org/10.1080/ 08039410.2005 .9666319$.

IUCN. (2003). The Durban Accord: Our commitment for people and Earth's protected areas [Online]. https://www.forestpeoples.org/en/topics/iucn/publication/2010/durban-accord-our-global-commi tment-people-and-earths-protected-areas. Accessed 12 June 2021.

IUCN. (2016a). Project guidelines and standards. Module 3 Project development version 2.2 rev 125 October 2016. Retrieved from: https://www.iucn.org/resources/project-management-tools/projectguidelines. Accessed 9 March 2021.

IUCN. (2016b). Project guidelines and standards. Module 5 evaluation and closure version 2.2. Retrieved from: https://www.iucn.org/resources/project-management-tools/project-guidelines. Accessed 9 March 2021.

Jepson, P., Barua, M., \& Buckingham, K. (2011). What is a conservation actor? Conservation and Society, 9, 229-235. https://doi.org/10.4103/0972-4923.86993.

Jost Robinson, C. A., \& Remis, M. J. (2018). Engaging holism: exploring multispecies approaches in ethnoprimatology. International Journal of Primatology, 39, 776-796. https://doi.org/10.1007/ s10764-018-0036-8.

Keller, E. S. (2008). The banana plant and the moon: conservation and the Malagasy ethos of life in Masoala, Madagascar. American Ethnologist, 35, 650-664. https://doi.org/10.1111/j.1548-1425. 2008.00103.x.

Keller, E. (2009). The danger of misunderstanding 'culture'. Madagascar Conservation and Development, 4, 82-85. https://doi.org/10.4314/mcd.v4i2.48647.

Klages, A. (2010). Triage: conserving primates and competing interests. TOTEM: The University of Western Ontario Journal of Anthropology, 18, 22-34. Retrieved from: https://ojs.lib.uwo.ca/index.php/ uwoja/article/view/8899. Accessed 24 March 2021.

Klein, C., McKinnon, M. C., Wright, B. T., Possingham, H. P., \& Halpern, B. S. (2015). Social equity and probability of success in biodiversity conservation. Global Environmental Change, 35, 299306. https://doi.org/10.1016/j.gloenvcha.2015.09.007.

Kohl, E., \& McCutcheon, P. (2015). Kitchen table reflexivity: negotiating positionality through everyday talk. Gender, Place and Culture, 22, 747-763. https://doi.org/10.1080/0966369X.2014.958063.

Kottak, C. P. (2005). Mirror for humanity: A concise introduction to cultural anthropology (4th ed.). McGraw-Hill.

Kutz, S., \& Tomaselli, M. (2019). “Two-eyed seeing” supports wildlife health. Science, 364, 1135-1137. https://doi.org/10.1126/science.aau6170.

Lappan, S., Malaivijitnond, S., Radhakrishna, S., Riley, E. P., \& Ruppert, N. (2020). The human-primate interface in the New Normal: challenges and opportunities for primatologists in the COVID-19 era and beyond. American Journal of Primatology, 82, e23176. https://doi.org/10.1002/ajp.23176.

Latulippe, N., \& Klenk, N. (2020). Making room and moving over: knowledge co-production, indigenous knowledge sovereignty and the politics of global environmental change and decision-making. Current Opinion in Environmental Sustainability, 42, 7-14. https://doi.org/10.1016/j.cosust.2019.10. 010 .

Lavenda, R. H., \& Schultz, E. A. (2000). Core Concepts in Cultural Anthropology. Mayfield Publishing Company.

LeCompte, M. D., \& Schensul, J. J. (1999). Designing \& conducting ethnographic research. AltaMira Press. 
Lee, P. C. (2010). Sharing space: Can ethnoprimatology contribute to the survival of nonhuman primates in human-dominated globalized landscapes? American Journal of Primatology, 72(10), 925-931. https://doi.org/10.1002/ajp.20789.

Lenkeit, R. E. (2004). Introducing Cultural Anthropology, second edition (p. 64). McGraw-Hill.

Locke, P. (2018). Multispecies ethnography. In The International Encyclopedia of Anthropology. John Wiley \& Sons, Ltd. https://doi.org/10.1002/9781118924396.wbiea1491.

Loudon, J. E., \& Sponheimer, M. (2016). Conservation: new potential for stable isotope analysis. In M. T. Waller (Ed.), Ethnoprimatology: primate conservation in the $21^{\text {st }}$ century (p. 399). Springer.

Madden, F., \& McQuinn, B. (2017). Conservation conflict transformation - addressing the missing link in wildlife conservation. In C. M. Hill, A. D. Webber, \& N. E. C. Priston (Eds.), Understanding conflicts about wildlife: a biosocial approach (pp. 148-169). Berghahn Books.

Maffi, L. (2005). Linguistic, cultural and biological diversity. Annual Review of Anthropology, 29, 599617. https://doi.org/10.1146/annurev.anthro.34.081804.120437.

Mallarach, J.-M. (2008). Cultural and spiritual values of protected landscapes and seascapes: an overview. In J.-M. Mallarach (Ed.), Protected landscapes and cultural and spiritual values (pp. 9-20). IUCN, GTZ and Obra Social de Caixa Catalunya: Kasparek Verlag.

Malone, N., Wade, A. A., Fuentes, A., Remis, M., \& Jost Robinson, C. (2014). Ethnoprimatology: critical interdisciplinarity and multispecies approaches in anthropology. Critique of Anthropology, 24, 8-29. https://doi.org/10.1177/0308275X13510188.

Mascia, M. B., Brosius, J. P., Dobson, T. A., Forbes, B. C., Horowitz, L., et al (2003). Conservation and the social sciences. Conservation Biology, 17, 649-650. https://doi.org/10.1046/j.1523-1739.2003. 01738.x.

Moller, H., Berkes, F., Lyver, P. O., \& Kislalioglu, M. (2004). Combining science and traditional ecological knowledge: monitoring populations for co-management. Ecology and Society, 9, 2. https://doi. org/10.5751/es-00675-090302.

Montana, J., Sandbrook, C., Robertson, E., \& Ryan, M. (2019). Revealing research preferences in conservation science. Oryx, 55, 1-8. https://doi.org/10.1017/S003060531900067X.

Montana, J., Elliot, L., Ryan, M., \& Wyborn, C. (2020). The need for improved reflexivity in conservation science. Environmental Conservation, 47, 217-219. https://doi.org/10.1017/S0376892920000326.

Moon, K., \& Blackman, D. (2014). A guide to understanding social science research for natural scientists. Conservation Biology, 28, 1167-1177. https://doi.org/10.1111/cobi.12326.

Moore, S. E., \& Hauser, D. D. W. (2019). Marine mammal ecology and health: finding common ground between conventional science and indigenous knowledge to track Arctic ecosystem variability. Environmental Research Letters, 14, 075001. https://doi.org/10.1088/1748-9326/ab20d8.

Nazaruk, M. (2011). Reflexivity in anthropological discourse analysis. Anthropological Notebooks, 17, 73-83 Retrieved from: http://www.drustvo-antropologov.si/AN/PDF/2011_1/Anthropological_ Notebooks_XVII_1_Nazaruk.pdf. Accessed 6 Feb 2022.

Nörstrum, A. V., Cvitanovic, C., Löf, M. F., West, S., Wyborn, C., et al (2020). Principles for knowledge co-production in sustainability research. Nature Sustainability, 3, 182-190. https://doi.org/10.1038/ s41893-019-0448-2.

O'Connell, D., Abel, N., Grigg, N. N., Maru, Y., Butler, J., et al. (2016). Designing projects in a rapidly changing world: Guidelines for embedding resilience, adaptation and transformation into sustainable development projects. (Version 1.0). Global Environment Facility, Washington, D.C. Retrieved from: https://www.stapgef.org/search/node?keys=RAPTA+guidelines. Accessed 24 March 2021.

Osterhoudt, S. (2018). Community conservation and the (mis)appropriation of taboo. Development and change, 49, 1248-1267. https://doi.org/10.1111/dech.12413.

Papworth, S., Milner-Gulland, E. J., \& Slocombe, K. (2013). The natural place to begin: the ethnoprimatology of the Waorani. American Journal of Primatology, 75, 1117-1128. https://doi.org/10.1002/ ajp. 22173 .

Parathian, H. E., McLennan, M. R., Hill, C. M., Frazão-Moreinra, A., \& Hockings, K. J. (2018). Breaking through disciplinary barriers: human-wildlife interactions and multispecies ethnography. International Journal of Primatology, 39, 749-775. https://doi.org/10.1007/s10764-018-0027-9.

Parthasarathy, N., \& Naveen Babu, K. (2019). Sacred groves: potential for biodiversity and bioresource management. In W. Leal Filho, A. M. Azul, L. Brandi, A. L. Salvia, \& T. Wall (Eds.), Life on Land, Encyclopedia of the UN Sustainable Development Goals (pp. 1-16). Springer.

Peacock, J. L. (2001). The anthropological lens: harsh light, soft focus (2nd ed.). Cambridge University Press. 
Peterson, G. D., Cumming, G. S., \& Carpenter, S. R. (2003). Scenario planning: a tool for conservation in an uncertain world. Conservation Biology, 17, 358-366. https://doi.org/10.1046/j.1523-1739.2003. 01491.x.

Peterson, R. B., Russell, D., West, P., \& Brosius, J. P. (2010). Seeing (and doing) conservation through cultural lenses. Environmental Management, 45, 5-18. https://doi.org/10.1007/s00267-008-9135-1.

Pretty, J., Adams, B., Berkes, F., De Athayde, S. F., Dudley, N., et al (2009). The intersections of biological diversity and cultural diversity: towards integration. Conservation and Society, 7, 100-112. https://doi.org/10.4103/0972-4923.58642.

Riley, E. P. (2006). Ethnoprimatology: Toward reconciliation of biological and cultural anthropology. Ecological and Environmental Anthropology, 2, 75-86 Retrieved from: https://digitalcommons. unl.edu/icwdmeea/8. Accessed 3 June 2020.

Riley, E. P. (2013). Contemporary primatology in anthropology: beyond the epistemological abyss. American Anthropologist, 115(3), 411-422 https://www.jstor.org/stable/24028765.

Riley, E. P. (2018). The maturation of ethnoprimatology: theoretical and methodological pluralism. International Journal of Primatology, 39, 705-729. https://doi.org/10.1007/s10764-018-0064-4.

Rodrigues, M. A. (2020). Neocolonial narratives of primate conservation [Blog post]. Retrieved from: https://human-primate-interactions.org/blog/ . Accessed 5 Jan 2021.

Rose, G. (1997). Situating knowledges: positionality, reflexivities and other tactics. Progress in Human Geography, 21, 305-320 https://doi.org/10.1191\%2F030913297673302122.

Rubis, J. M. (2020). The orang utan is not an indigenous name: knowing and naming the maias as a decolonizing epistemology. Cultural Studies, 34, 811-830. https://doi.org/10.1080/09502386.2020. 1780281.

Rubis, J. M., \& Theriault, N. (2019). Concealing protocols: conservation, indigenous survivance, and the dilemmas of visibility. Social \& Cultural Geography, 21, 962-984. https://doi.org/10.1080/14649 365.2019.1574882.

Ryan, R. M., \& Deci, E. L. (2000). Self-determination theory and the facilitation of intrinsic motivation, social development, and well-being. American Psychologist, 55, 68-78. https://doi.org/10.1037/ 110003-066X.55.1.68.

Salzman, P. C. (2002). On reflexivity. American Anthropologist, 104, 805-811. https://doi.org/10.1525/ aa.2002.104.3.805.

Setchell, J. M. (2020). Decolonising primatology [Plenary talk]. Primate Society of Great Britain Winter Meeting. Primate Society of Great Britain, 1-2 December 2020. Online, p3.

Setchell, J. M., Fairet, E., Shutt, K., Waters, S., \& Bell, S. (2017). Biosocial conservation: integrating biological and ethnographic methods to study human-primate interactions. International Journal of Primatology, 38, 401-426. https://doi.org/10.1007/s10764-016-9938-5.

Singh, S., Youssouf, M., Malik, Z. A., \& Bussmann, R. W. (2017). Sacred groves: Myths, beliefs, and biodiversity conservation - a case study from Western Himalaya, India. International Journal of Ecology, 2017, 1-12. https://doi.org/10.1155/2017/3828609.

Sterling, E. J., Filardi, C., Toomey, A., et al (2017). Biocultural approaches to well-being and sustainability indicators across scales. Nature Ecology and Evolution, 1(12), 1798-1806. https://doi.org/ 10.1038/s41559-017-0349-6.

Tengö, M., Brondizio, E. S., Elmqvist, T., Malmer, P., \& Spierenburg, M. (2014). Connecting diverse knowledge systems for enhanced ecosystem governance: the multiple evidence based approach. Ambio, 43, 579-591. https://doi.org/10.1007/s13280-014-0501-3.

Tomaselli, M., Kutz, S., Gerlach, C., \& Checkley, S. (2018). Local knowledge to enhance wildlife population health surveillance: conserving muskoxen and caribou in the Canadian Arctic. Biological Conservation, 217, 337-348. https://doi.org/10.1016/j.biocon.2017.11.010.

Turnhout, E., Metze, T., Wyborn, C., Klenk, N., \& Louder, E. (2020). The politics of co-production: participation, power, and transformation. Current Opinion in Environmental Sustainability, 42, 15021. https://doi.org/10.1016/j.cosust.2019.11.009.

Van Dooren, T., Kirksey, E., \& Münster, U. (2016). Multispecies studies: Cultivating arts of attentiveness. Environmental Humanities, 8, 1-23. https://doi.org/10.1215/22011919-3527695.

Van Patter, L. E., \& Blattner, C. (2020). Advancing ethical principles for non-invasive, respectful research with nonhuman animal participants. Society and Animals, 28, 171-190. https://doi.org/10.1163/ 15685306-00001810.

Vining, J., Merrick, M. S., \& Price, E. A. (2008). The distinction between humans and nature: human perceptions of connectedness to nature and elements of the natural and unnatural. Human Ecology Review, 15(1), 1-11 https://www.jstor.org/stable/24707479. Accessed 8 Oct 2021. 
Vivanco, L. A. (2018). Reflexivity. In L. A. Vivanco (Ed.), A dictionary of cultural anthropology. Oxford University Press. https://doi.org/10.1093/acref/9780191836688.001.0001.

Walker, B., Holling, C. S., Carpenter, S. R., \& Kinzig, A. (2004). Resilience, adaptability and transformability in social-ecological systems. Ecology and Society, 9, 5. https://doi.org/10.5751/ es-00650-090205.

Walker, B., Abel, N., O’Connell, D., \& Grigg, N. (2016). A resilience approach to conservation and development: Working paper version 1.5. CSIRO. https://doi.org/10.4225/08/58542cd5577d2.

Wallis, J., \& Lonsdorf, E. V. (2010). Summary of recommendations for primate education programs. American Journal of Primatology, 72, 441-444. https://doi.org/10.1002/ajp.20764.

Waters, S., Harrad, A. E., Bell, S. and Setchell, J. M (2020). Interpreting people's behavior toward primates using qualitative data: a case study from north Morocco. International Journal of Primatology, 40(3), 316-330. https://doi.org/10.1007/s10764-019-00087-w.

Waters, S., Harrad, A. E., Bell, S., \& Setchell, J. M. (2021). Decolonizing primate conservation practice: a case study from North Morocco. International Journal of Primatology. https://doi.org/10.1007/ s10764-021-00228-0.

Welch-Devine, M., Hardy, D., Brosius, J. P., \& Heynen, N. (2014). A pedagogical model for integrative training in conservation and sustainability. Ecology and Society, 19, 10. https://doi.org/10.5751/ ES-06197-190210.

West, P., Igoe, J., \& Brockington, D. (2006). Parks and peoples: The social impact of protected areas. Annual Review of Anthropology, 35, 251-277. https://doi.org/10.1146/annurev.anthro.35.081705. 123308. 